\title{
Design, Analysis and Finite Element Modeling of Macro Fiber Composite Piezoelectric Materials ${ }^{\dagger}$
}

\author{
Dounia El Fadlaoui ${ }^{1}$, Brahim Boubeker ${ }^{1}$, Mohamed Idiri ${ }^{1}$, Soukaina Essaket ${ }^{1}$ \\ 1 Laboratory of Engineering and Materials (LIMAT) / Faculty of Science Ben M'Sik, Hassan II University, Casablanca, \\ Morocco \\ * Correspondence: douniaaelfadlaoui@gmail.com; \\ $\dagger$ Presented at Materials Chemistry and Physics (Materials Chemistry 2020) - International e-Conference
}

Received: 16.09.2020; Revised: 20.09.2020; Accepted: 24.09.2020; Published: 27.09.2020

\begin{abstract}
Vibration energy harvester has been paid a lot of attention by many researchers to transforming ambient vibration into electrical energy, which is normally utilized to develop wireless electronic sectors. The paper presents a finite element model (FEM) of a vibration energy harvester consisting of a bimorph electromechanical system (MEMS) generator. The model is used to simulate, and compare, the mechanical characteristics and electrical response of piezoelectric material results between the cantilever beam structure formed by laminating two piezoelectric layers on both sides of a Carbon fiber reinforced polymer (CFRP) substrate and Ti-6Al-4V substrate using ANSYS®19 R1. A set of numerical simulations has been carried out, and the results show that the comparisons of the harmonic response analysis seen change between the different substrates based on the bimorph piezoelectric MEMS generator.
\end{abstract}

Keywords: FEM; MEMS; CFRP; ANSYS; cantilever beam.

(C) 2020 by the authors. This article is an open-access article distributed under the terms and conditions of the Creative
Commons Attribution (CC BY) license (https://creativecommons.org/licenses/by/4.0/).

\section{Funding}

This research received no external funding.

\section{Acknowledgments}

The authors declare no acknowledgments.

\section{Conflicts of Interest}

The authors declare no conflict of interest. 